\title{
Inovação educacional no século XIX: A construção do currículo da escola primária no Brasil
}

\author{
Rosa Fátima de Souza*
}

\begin{abstract}
RESUMO: O texto busca reconstituir o processo de renovação dos programas da escola primária engendrado no Brasil a partir de 1870, situando a modernização educacional no país em relação ao contexto internacional. Para este estudo utilizamos como fonte de pesquisa 0 parecer de Rui Barbosa acerca da Reforma do ensino primário e várias instituições complementares da instrução pública (1883), em especial o volume concernente à discussão sobre métodos e o programa escolar. A análise efetuada mostra que a renovação do programa escolar significou para as camadas populares maiores oportunidades de acesso à cultura. Demostra, também, como o programa constitui um projeto político social civilizador, direcionado para a construção da nação, a modernização do país e a moralização do povo.
\end{abstract}

Palavras-chave: História do ensino primário, história do currículo, cultura escolar, currículo do ensino primário, história das disciplinas escolares

Desde a segunda metade do século XIX, a questão política da educação popular envolveu, em todo o Ocidente, a discussão sobre a organização administrativa e didático-pedagógica do ensino primário. Tratou-se de definir as finalidades da escola primária e os meios de sua universalização. Esse processo implicou debates acerca da democratização da cultura e da função política da escola nas sociedades modernas. Dessa forma, a discussão sobre o conteúdo da escolarização popular tornou-se uma temática central e oscilou em decorrência de diferentes interesses políticos, ideológicos, religiosos, sociais, econômicos e culturais.

* Professora Doutora do Departamento de Ciências da Educação - Faculdade de Ciências e Letras da Unesp - Campus de Araraquara. E-mail: rosa@flcar.unesp.br 
Este texto busca reconstituir o processo de renovação dos programas da escola primária engendrado no Brasil a partir de 1870, situando a modernização educacional no país em relação ao contexto internacional.

Para realizar esta análise, utilizamos, como principal fonte de pesquisa, o parecer de Rui Barbosa acerca da Reforma do ensino primário e várias instituições complementares da instrução pública (1883), ${ }^{1}$ em especial o volume concernente à discussão sobre métodos e programa escolar (volume V, tomo II, das Obras Completas de Rui Barbosa). Esse documento constitui uma das primeiras obras, e a mais completa delas, sobre a organização pedagógica da escola primária e sobre política de educação popular produzida no Brasil no século XIX. ${ }^{2}$

Designado como relator da Comissão de Instrução Pública, ao estudo do projeto, Rui Barbosa buscou documentar amplamente o substitutivo tomando como referência farto material bibliográfico especializado vindo do exterior. Conforme indicações de Lourenço Filho, ${ }^{3}$ no parecer sobre o ensino primário foram citados 365 trabalhos, 179 em língua francesa, 129 em língua inglesa, 26 em português, 5 obras em língua alemã, 4 em italiano e 5 em espanhol. Muitas dessas obras referenciadas por Rui foram publicadas entre 1880 e 1882.

Essa extensa documentação permite, pois, apreender as representações educacionais em voga na época, seja no âmbito nacional ou internacional. Possibilita, ainda, explicitar o processo de construção do currículo da escola primária no Brasil, tendo em vista os determinantes sociais e políticos que orientaram a seleção cultural para esse nível de ensino, os interesses subjacentes e as forças sociais que influenciaram a inclusão de alguns saberes e disciplinas no programa escolar (Goodson 1995; 1997).

Como Faria Filho (1999) tem buscado demonstrar em seus trabalhos, é preciso ver a legislação como uma prática ordenadora das relações sociais. É nesta perspectiva que buscamos examinar o parecer sobre a reforma do ensino primário, isto é, como uma forma discursiva de intervenção social e de produção de práticas. Em realidade, muitas das concepções e propostas contidas no parecer foram adotadas nas reformas da instrução pública realizadas em várias províncias na década de 1880 , e posteriormente pelos estados nas primeiras reformas educacionais da era republicana. 


\section{A renovação do ensino e a circulação de modelos}

No decorrer do século XIX, conteúdo e método de ensino fizeram parte do intenso debate sobre a questão política da educação popular e os meios para efetivá-la, entre eles, a melhor organização pedagógica para a escola primária. Em toda parte, difundiu-se a crença no poder da escola como fator de progresso, modernização e mudança social. A idéia de uma escola nova para a formação do homem novo articulou-se com as exigências do desenvolvimento industrial e o processo de urbanização.

O fenômeno de âmbito mundial foi alimentado pela circulação de idéias e modelos gerados nos países ditos "civilizados" na época. Os mais variados temas da organização escolar tornaram-se objeto da reflexão política e pedagógica: métodos de ensino, a ampliação dos programas com a inclusão de novas disciplinas, livros e manuais didáticos, a classificação dos alunos, a distribuição dos conteúdos e do emprego do tempo, o mobiliário, materiais escolares, certificados de estudos, a arquitetura, a formação de professores, a disciplina escolar.

Diversos meios possibilitaram a circulação dessas idéias e modelos: as Exposições Universais, os congressos de instrução, relatórios oficiais elaborados por ministros e inspetores do ensino, publicações de livros, artigos, jornais e revistas especializadas no campo educacional.

É neste contexto que se compreende por que as idéias de renovação do ensino e o modelo de escola graduada direcionado para a escolarização em massa tiveram grande aceitação, sendo adotados em inúmeros países desenvolvidos e em desenvolvimento. Em que pesem as particularidades locais, o fenômeno da escolarização em massa, configurado a partir da segunda metade do século XIX, apresentou muitos aspectos comuns de abrangência global, entre eles: a obrigação escolar, a responsabilidade estatal pelo ensino público, a secularização do ensino e a secularização da moral, a nação e a pátria como princípios norteadores da cultura escolar, a educação popular concebida como um projeto de integração ideológica e política (Petitat 1994).

A propósito, os estudos de Meyer et al. (1992) atestam uma certa homogeneidade verificada nos currículos das escolas primárias nos países que desenvolveram os sistemas nacionais de ensino. Na mesma direção, Kames e Cha (1999) identificam nesses currículos um forte vínculo com a formação da nação. E Petitat (1994) lembra-nos de que, na reorganização dos 
programas escolares, várias disciplinas, tais como leitura, escrita, história, geografia, economia, direito, encontravam sua substância na própria realidade nacional.

Além disso, a introdução de novas disciplinas nos programas do ensino primário, especialmente ciências, desenho e educação física, articulou-se com a linguagem da modernidade, isto é, a justificativa para a inclusão desses conteúdos culturais assinalava as contribuições que eles trariam para a modernização.

Dessa forma, a construção dos Estados-nação e a modernização social tornaram-se os pilares sobre os quais se alicerçaram os ideais e as políticas de inovação educacional no final do século XIX e início do século XX.

No Brasil não foi diferente. No final do século XIX, a escola popular foi elevada à condição de redentora da nação e de instrumento de modernização por excelência.

Isso pode ser claramente percebido no substitutivo de reforma do ensino primário apresentado por Rui Barbosa, cujos argumentos centrais consideravam a imprescindibilidade da renovação pedagógica e a inspiração no modelo dos países avançados. A estratégia instituinte do reformador buscou a afirmação do novo pela contundente desqualificação das escolas e das práticas vigentes.

No lugar, Rui advogava uma escola primária obrigatória e laica com oito anos de duração dividida em três graus: o elementar e o médio, cada um com dois anos de duração, e o superior, com quatro anos. Na visionária concepção do legislador, a reforma do ensino primário deveria fundar uma nova realidade educacional no país substituindo a inócua escola de primeiras letras, voltada para o passado, pela escola primária moderna, com um ensino renovado e um programa enciclopédico, direcionada para o progresso do país.

O método intuitivo, conhecido também como lições de coisas, consistiu no núcleo principal da renovação pedagógica. Fundamentado especialmente nas idéias de Pestalozzi e Froebel, pressupunha uma abordagem indutiva pela qual o ensino deveria partir do particular para o geral, do conhecido para o desconhecido, do concreto para o abstrato.

Esse método racional fundamentava-se em uma concepção filosófica e científica pela qual a aquisição de conhecimentos advinha dos sentidos e da observação. A racionalidade pedagógica articulava-se com os princípios de 
racionalização da produção e da vida social e possivelmente isso justifique a confiança e o fascínio que ele provocou naquele momento. ${ }^{4}$

No parecer de Rui sobre a reforma do ensino primário, o método intuitivo foi exaltado como o elemento mais importante de toda a reforma: "Cumpre renovar o método, orgânica, substancial, absolutamente, nas nossas escolas. Ou antes, cumpre criar o método..." (Barbosa 1883, p. 61-62). ${ }^{5}$ Somente esse método poderia triunfar sobre o ensino verbalista, repetitivo, enraizado na memória e nas abstrações inúteis praticado nas escolas de primeiras letras do Império. Ele deveria constituir-se em um princípio geral abrangendo todo o programa e não um assunto específico, um item entre o rol de matérias como Leôncio de Carvalho introduzira as "lições de coisas" na reforma de 1879. A indubitável relevância do método era atestada por Rui:

As lições de coisas, antevistas por esses espíritos precursores, e levadas a um alto grau de desenvolvimento no método froebeliano, são hoje abraçadas e exigidas, como ponto de partida de todo o ensino, em todos os países adiantados e por todos os pedagogos eminentes. (ibidem)

De acordo com o relator, as "lições de coisas", esses exercícios do pensamento que já se encontravam vulgarizados na Alemanha havia mais de 70 anos, também eram adotadas na Suécia, na França, na Bélgica, na Itália e nos Estados Unidos. O reformador tinha clareza quanto à profundidade da renovação proposta, especialmente quanto às exigências para o trabalho docente. O método intuito requeria do mestre "mais presença de espírito, mais benevolência de ânimo, mais recursos intelectuais - em suma, um esmerado cultivo da vocação pedagógica" (ibidem).

Juntamente com o método era imperiosa a reorganização do programa escolar. A esse respeito, Rui segue mais uma vez as idéias pedagógicas predominantes na época, isto é, a ampliação do programa escolar justificada pelo princípio da educação integral: educação física, intelectual e moral.

Tal princípio, formulado e difundido a partir da obra de Spencer, Educação Intellectual, Moral e Physica, publicada em 1861, coadunava uma concepção de educação com as aspirações e necessidades da sociedade moderna. $O$ apelo de Spencer à correspondência entre a lei da evolução biológica (lei do desenvolvimento orgânico) e o progresso social possibilitou a naturalização da evolução da sociedade e a compreensão da ciência como 
o conhecimento mais relevante, o conhecimento útil com aplicação no trabalho, na arte e na vida diária.

Nesta concepção, corpo e espírito são indissociáveis. O princípio da educação integral expressava essa compreensão unificada pela qual a educação seguia as leis da natureza e a ciência revelava-se como o melhor meio para a disciplina intelectual e a disciplina moral (Spencer 1884, p. 67). Essa visão era compartilhada por Rui, para quem

(...) o que, portanto, cumpre, é repudiar absolutamente o que existe, e reorganizar inteiramente de novo o programa escolar, tendo por norma esta lei suprema: conformá-lo com as exigências da evolução, observar a ordem natural, que os atuais programas invertem (...). Demonstra-se a perfeita racionalidade desse critério, aplicado à educação científica do homem, pela identidade exata entre a progressão que seguem as faculdades humanas no desenvolvimento natural, biológico, espontâneo do indivíduo e da espécie. (Barbosa 1883, p. 58)

A educação integral converteu-se no primeiro fundamento pedagógico sistemático para a seleção dos conteúdos para a escola primária. A definição de uma nova cultura escolar para o povo encontrou justificações filosóficas e pedagógicas para amparar um projeto de fundo político e social.

\section{Uma política cultural para a modernização do país}

Disputas e debates marcaram a configuração do currículo do ensino primário e secundário no Ocidente, no decorrer do século XIX. Nesse processo estiveram em jogo a substituição de uma cultura literária pela cultura científica no ensino secundário e a difusão de conhecimentos úteis de natureza social, moral e cívica no ensino primário.

A renovação pedagógica e a constituição de currículos modernos não alteraram, contudo, o caráter de distinção de classe próprio da educação burguesa: o ensino secundário de cultura geral para a formação das elites e o ensino primário voltado para a formação dos trabalhadores.

De fato, a educação científica teve um papel fundamental na redefinição da cultura escolar para o povo e para as elites. No ensino secundário o debate girou em torno da cultura humanística ou clássico-literária e a cultura moderna, 
cujas referências ancoravam-se no progresso científico e no caráter nacional (língua e literatura do país, história e geografia). Mesmo os ardorosos defensores da introdução das ciências nos programas não abriram mão do caráter distintivo de classe predominante no ensino secundário. Dessa forma, a redefinição dos currículos objetivou atualizar e ampliar a cultura geral das elites mediante $o$ aprofundamento dos estudos em ciências e letras, colocando os jovens em contato com os novos temas culturais de seu tempo (Petitat 1994).

Além dos conflitos motivados por interesses políticos e sociais na definição dos currículos é preciso reconhecer as disputas internas de caráter teórico e metodológico no âmbito das comunidades científicas e profissionais - questão pertinente à história da ciência e das disciplinas escolares. ${ }^{6}$

Em relação ao ensino primário, assim como ler, escrever e contar foram o resultado da escolarização de saberes profissionais, como demonstra Hébrard (1990), pode-se dizer que, no século XIX, assistimos à escolarização de vários outros saberes sociais, além do conhecimento científico, como, por exemplo, a ginástica, a música e o canto, os valores morais e cívicos, o desenho, a escrituração mercantil, o sistema de pesos e medidas, as noções de horticultura e arboricultura, os trabalhos manuais, a higiene, a puericultura, a economia doméstica, entre outros.

Mesmo o conhecimento científico, cujo processo de especialização resultou nas disciplinas específicas, foi incorporado na escola primária com características muito peculiares, isto é, em forma de rudimentos ou noções vinculadas fortemente à metodologia de ensino.

Em realidade, não apenas o conhecimento científico mas, em geral, todos os conteúdos do ensino primário constituíram-se em saberes escolarizados fruto de um intenso processo de transposição didática. É isso que permite reconhecer nesse nível de ensino as indicações de Chervel (1990) acerca da cultura escolar vista como criação sui generis da escola.

No parecer sobre a reforma do ensino primário, Rui Barbosa propôs um programa enciclopédico tendo em vista a necessidade de ampliação da cultura escolar para o povo, isto é, a formação de uma classe trabalhadora conformada às exigências do desenvolvimento econômico e social do país. Esse programa compreendia: educação física, música e canto, desenho, língua materna, rudimentos das ciências físicas e naturais, matemática e taquimetria, geografia e cosmografia, história, rudimentos da economia política e cultura moral e cívica. Ciente da profundidade da inovação sugerida, Rui não poupou esforços em justificar de forma meticulosa a presença de cada um 
dos assuntos componentes do programa escolar. Para apoiar seus argumentos, serviu-se o relator de abundantes citações de documentos oficiais e da opinião de pedagogos, cientistas, médicos, higienistas e autoridades do ensino de renome internacional, uma vez que,

(...) num país onde maior do que a ignorância geral não há talvez nada senão a presunção de ciência, que a acompanha, o exemplo do que se passa entre outros povos, autenticado por textos de competência irrefragável, é a mais essencial e concludente de todas as demonstrações possíveis. (Ibidem, p. 91)

Dessa forma, foram selecionados para o programa aqueles conteúdos que, na opinião do legislador, melhor atendiam às finalidades de modernização do país e de formação das camadas populares; conteúdos que correspondessem ao princípio da educação integral e fossem atestados pelos países mais civilizados.

Para as finalidades deste estudo, interessa-nos destacar a concepção de ensino de cada uma das matérias propostas, as finalidades a elas atribuídas e as indicações metodológicas correspondentes.

A introdução da educação física foi apresentada como uma inovação relevante. A satisfação da vida física era a primeira necessidade da infância, justificando, assim, a importância fundamental da ginástica num plano de estudos que postulava a inseparabilidade do espírito e do corpo. De acordo com Rui, a educação física havia sido introduzida nos programas de ensino de vários países tendo em vista sua função moralizadora, higiênica e patriótica. O substitutivo destaca as finalidades morais e sociais da ginástica: agente de prevenção dos hábitos perigosos da infância, meio de constituição de corpos saudáveis, fortes e vigorosos, instrumento contra a degeneração da raça, ação disciplinar moralizadora dos hábitos e costumes responsável pelo cultivo dos valores cívicos e patrióticos imprescindíveis à defesa da pátria.

Deveria a ginástica se estender para o sexo feminino? Rui registra o debate em voga e posiciona-se favorável à diferenciação dos programas.

Para o sexo feminino, era a favor da calistenia, "nessa combinação de exercícios de movimento, engenhados por Adolfo Spiess e destinados a produzirem um simétrico desenvolvimento muscular sem prejuízo da doçura das maneiras, da graça e elegância do talhe, da bela harmonia das formas femininas" (ibidem). 
Para os meninos, a ginástica acrescida dos exercícios militares, meio eficaz para a educação do caráter, validado por todos os países avançados:

Seria, portanto, uma lacuna imperdoável a omissão dos exercícios militares num plano de reorganização do ensino popular. Quer como meio de lançar nos hábitos da mocidade a base da defesa nacional, quer como escola das virtudes varonis do patriotismo, quer como princípio influidor de elevadas qualidades morais, este ramo de instrução encerra um valor considerável, e representa um papel essencial. (Ibidem, p. 92).

Como demonstram os estudos de Soares (1994; 1998), Vago (1999) e Neto (1997), a educação física foi introduzida no Brasil, tributária das concepções do movimento ginástico europeu em sua versão disciplinar do corpo. Sobre esse corpo tomado como objeto discursivo recaíram concepções sobre a moral, a saúde, a produtividade no trabalho. De acordo com Soares (1994), a educação física das crianças no Brasil emerge atuando na preparação do corpo feminino para a reprodução dos filhos da pátria e na preparação do corpo do soldado tornando-o útil à pátria e ao capital.

Ainda como parte da educação física, a música e o canto foram indicados como conteúdos essenciais no programa do ensino primário. A relevância desse conteúdo para a formação do homem moderno pode ser atestada pelas palavras de Guizot, citadas por Rui:

A música produz n'alma uma verdadeira cultura interior, e faz parte da educação do povo. Tem por efeito desenvolver os vários órgãos do ouvido e da palavra, adoçar os costumes, civilizar as classes inferiores, aligeirar para elas as fadigas do trabalho, e proporcionar-lhes um inocente prazer, em vez de distrações muita vez grosseiras e arruinadoras. (Barbosa 1883, p. 103)

Vemos, assim, como a cultura musical foi introduzida na escola primária tendo em vista seu caráter moral e utilitário. A evolução do ensino da música no Brasil ocorreu acentuando os valores cívico-patrióticos e a dulcificação dos costumes.

O desenho foi considerado por Rui como uma das matérias fundamentais do programa da escola elementar e recebeu um destaque 
especial no parecer. O entusiasmo de Rui pelo desenho fazia eco à opinião de industriais, pedagogos e autoridades do ensino dos países adiantados que viam a potencialidade da escolarização desse saber profissional para o desenvolvimento econômico. Por conseguinte, o desenho foi ressaltado como fonte de riqueza, como elemento essencial à prosperidade do trabalho.

A esse conteúdo foi atribuída uma finalidade essencialmente prática que se ajustava às necessidades da indústria e da arte. Deste ponto de vista, para o operário a aprendizagem do desenho era tão importante quanto a aprendizagem da leitura e da escrita. Tratava-se, sobretudo, do domínio de uma aprendizagem técnica, profissional. De acordo com Rui, não por acaso, a Inglaterra e os Estados Unidos haviam-no considerado uma das bases primordiais da cultura escolar.

Quais conteúdos do desenho deveriam ser ensinados e por quais métodos? A esta questão, Rui buscou responder descrevendo, com riqueza de detalhes, as proposições dos métodos americano, austríaco e inglês. A preferência do relator incidiu sobre os dois últimos, tendo em vista os frutos maravilhosos que vinham apresentando em seus países. O método inglês consistia na graduação do desenho considerando: a) o desenho de memória (cópias e objetos); b) o desenho de invenção (composição com elementos já aprendidos); c) o desenho a tempo fixo (exercícios tirados da escala do ensino imediatamente inferior à capacidade do discípulo).

O método austríaco referia-se ao processo estignográfico, sistematizado por Grandauer, compreendendo a aprendizagem metódica das formas geométricas elementares pelo uso do papel quadriculado permitindo, dessa forma, a transição natural do desenho auxiliado para o desenho a olho, sem o auxílio de régua e compasso. Dessa forma, o relator justificava sua opção:

Ora, esses dois métodos, longe de se oporem, e excluírem, são, pelo contrário, complementos um do outro, constituindo o programa inglês o curso do desenho elementar preparatório, o tirocínio preliminar ao desenho elementar propriamente dito, ao desenho elementar graduado, cujo plano tem o seu diretório judiciosamente compendiado no livro de Grandauer. O ensino do desenho, pois, segundo o concebemos, deve começar na escola elementar, entre as crianças de 7 anos, pelo método inglês, que se estenderá até a escola do segundo grau, a escola média, onde se principiará a professar, pelo sistema austríaco, o desenho elementar graduado. (ibidem) 
Outra questão em debate era a quem competia o ensino do desenho na escola primária, se aos professores primários ou a professores especiais. Valendo-se do ponto de vista de W. Smith e Stetson, Rui atribuiu ao professor primário tal competência asseverando a necessidade de uma preparação especial a ser realizada na Escola Normal Nacional de Arte Aplicada, cuja estrutura e cuja organização foram também contempladas no plano da reforma.

Na história do currículo da escola primária no Brasil, a história do ensino do desenho merece um estudo aprofundado. Juntamente com outros conteúdos, tais como trabalhos manuais, noções de agricultura e horticultura e seus desdobramentos posteriores na década de 1870 , com a iniciação ao trabalho e as práticas industriais, comerciais, agrícolas e a educação para o lar, a escolarização desses saberes profissionais, transformados em saberes escolares, revela a natureza da cultura escolar para o povo e as tentativas de instrumentalização profissional do trabalhador, desde o início do seu processo de escolarização.

Em relação à língua materna, as considerações apresentadas para a renovação do programa escolar dizem respeito, mais especificamente, à aplicação do método intuitivo ao ensino da língua e uma crítica mordaz contra o ensino da gramática.

Como em todos os outros assuntos do programa, a intuição foi apontada como a base do ensino. Dessa forma, a criança deveria aprender a língua falando, pois, "no primeiro período da aula de primeiras letras, o estudo da língua há de se confundir com as lições de coisas, apoiar-se exclusivamente nelas" (ibidem). No plano da reforma, o ensino da gramática teria início apenas a partir da $3^{\underline{a}}$ série do ensino primário. Mas se tratava de uma outra concepção de gramática, não a tradicional mas a gramática orientada pelos princípios científicos modernos, isto é, aquela que se apresentava "como um produto histórico, como a carta da evolução da língua e como ciência da observação estrita" (ibidem). Em decorrência, seria pelo exercício da linguagem que o aluno preparar-se-ia para deduzir a teoria sobre a língua e suas leis.

Também em relação à matemática, o substitutivo teve pouco a acrescentar a não ser em relação ao método empregado. A esse respeito, sobressaem os métodos concretos que precedem as operações escritas e 0 uso formal e metódico dos algarismos. A utilidade do cálculo mental foi reconhecida desde que praticado sem o caráter abstrato mas mediante problemas de aplicação usual e próximos da vida das crianças.

Para a prática efetiva do ensino de geometria o parecer indicou a adoção da taquimetria, método de ensino de geometria criado pelo engenheiro de 
pontes e calçadas Eduardo Lagout, que, na opinião de Rui, significava a concretização da geometria, isto é, "o ensino da geometria pela evidência material, a acomodação da geometria à inteligência mais rudimentar: é a lição de coisas aplicada à medida de extensões e volumes" (ibidem).

Como mostra Valente (1999), já no ano de 1827, um projeto de lei previa a introdução de noções de geometria elementar nas escolas de primeiras letras. Tal projeto, porém, gerou muita polêmica, uma vez que muitos defendiam o ensino de geometria no curso secundário e não no primário. $O$ debate atravessou o século XIX. Desde o início, os partidários das noções elementares da geometria no ensino primário assinalavam o caráter útil dessas noções para a vida prática. No parecer acerca da reforma do ensino primário, Rui reafirma a contribuição prática desse conteúdo e insiste na necessidade do seu ensino nas escolas de primeiras letras.

Uma sensibilidade para o valor aplicado e econômico da ciência intensificou-se na segunda metade do século XIX. Spencer expressou bem a concepção moderna do papel social da ciência na sociedade e na educação ao apontá-la como o conhecimento de maior valor:

Assim, para a pergunta que formulamos - quais são os conhecimentos de maior valor? - há uma resposta uniforme - a Ciência. É o veredicto para todas as interrogações. Para a direta conservação própria, para a conservação da vida e da saúde, o conhecimento mais importante é a Ciência. Para a indireta conservação própria, o que se chama ganhar a vida, o conhecimento de maior valor é a Ciência. Para o justo desempenho das funções da família, o guia mais próprio só se encontra na Ciência. Para a interpretação da vida nacional, no passado e no presente, sem o qual o cidadão não pode justamente regularizar o seu procedimento, a chave indispensável é a Ciência. Para a produção mais perfeita e para os gozos da arte em todas as suas formas, a preparação imprescindível é ainda a Ciência, e para os fins da disciplina intelectual, moral e religiosa o estudo mais eficaz é, ainda, uma vez, a Ciência. (Spencer 1884, p. 67)

Para esse autor, a ciência era o conhecimento que melhor revelava o sentido do progresso e da sociedade civilizada. Por isso, ela sobressaía como um conhecimento essencial para a vida moderna, o conhecimento útil e válido cujas verdades podiam ser aplicadas aos mais variados negócios da vida prática: na indústria, no trabalho, na conservação da saúde, no exercício dos deveres políticos e sociais, na condução da vida moral. 
Em realidade, a Inglaterra foi um dos países pioneiros no desenvolvimento do ensino de ciências, como mostram os estudos de Goodson (1997). ${ }^{8}$

Foi justamente na experiência inglesa que Rui buscou os primeiros argumentos para justificar a adoção dos rudimentos das ciências físicas e naturais no programa do ensino primário brasileiro. No substitutivo, a relevância do ensino de ciências foi ressaltada considerando a sua contribuição para o desenvolvimento intelectual da criança gerando hábitos de curiosidade, observação, investigação e sua contribuição para o desenvolvimento econômico e o progresso industrial.

A indicação metodológica foi mais uma vez as lições de coisas, de modo natural factíveis ao ensino da natureza. Cumpria, pois, extirpar a pedagogia retórica com base em nomes, datas, definições, preceitos, lições, formas de impenetrável verbalismo. Ao contrário, o ensino de ciências pressupunha o contato com os objetos e a observação. O processo de ensino haveria de seguir as leis que presidiam o próprio conhecimento científico, isto é, a observação e a experimentação.

Os desafios da educação científica eram muitos e demandavam um mestre diferenciado: "Deste encargo não conseguirá desempenhar-se o preceptor, sem que a sua preparação científica se efetue solidamente, habituando-o à investigação direta das coisas na sua realidade natural" (Barbosa 1883). Demandavam, ainda, o uso de materiais didáticos, por exemplo, as coleções de mineralogia, botânica, zoologia, como recomendavam os pedagogos americanos.

Os opositores ao ensino de ciências no ensino elementar alegavam que ele não estava ao alcance das crianças e, além disso, necessitava de mestres com talentos enciclopédicos e escolas equipadas com custosos gabinetes, laboratórios e oficinas. ${ }^{9}$

Os defensores da cultura científica nas escolas rebatiam as críticas enfatizando as vantagens econômicas e pedagógicas desse ensino e reforçando a sua natureza peculiar no ensino primário, ou seja, as noções elementares fundamentadas no conhecimento próximo à criança e na vida prática utilizando objetos e materiais do meio. Dessa forma, importava menos a assimilação de conceitos e fatos, outrossim, o desenvolvimento de habilidades intelectuais básicas, uma certa apreensão elementar do conhecimento da natureza que habilitasse o futuro trabalhador a adaptar-se à sociedade moderna. 
A configuração do currículo moderno para a escola primária constituiu-se durante o século XIX, mediante um trabalho intenso de adaptação das ciências naturais e sociais ao nível da aprendizagem infantil; é o caso, por exemplo, do ensino da gramática, da matemática, da geometria, das ciências, da história e da geografia. ${ }^{10}$ As lições de coisas possibilitaram e, de certa forma, potencializaram a tradução do conhecimento científico em noções elementares para o uso nas escolas. O parecer, aqui analisado, deixa transparecer os enfrentamentos para a constituição desses saberes.

Isso pode ser claramente observado em relação ao ensino da geografia que foi apresentado por Rui como um desdobramento natural da lição de coisas, com ela se confundindo no início da escolarização e no espírito de seus processos. Convinha, pois, que o ensino iniciasse pelas lições de lugar, pelo conhecimento do meio mais próximo - a escola, o bairro, o distrito, para depois deter-se na província, no reino, nos outros países. O método consistia em partir da observação, único recurso capaz de dar concreticidade aos dados $e$ às definições. $\mathrm{Na}$ impossibilidade da observação direta dos fenômenos, as lições deveriam partir sempre do conhecido para o desconhecido utilizando objetos familiares aos alunos.

Esse mesmo procedimento aplicava-se ao ensino da cosmografia ensino elementar da astronomia - e ao ensino da cartografia.

No ensino da geografia era todo o universo da natureza que se descortinava, por isso era imprescindível estar atento ao método, ao uso de bons livros e materiais didáticos, tais como planetários, globos terrestres, cartas em relevo, cartas planas e cartas escolares parietais.

Quanto ao ensino da história, o substitutivo deixa entrever as dificuldades de adaptação do conhecimento histórico ao ensino primário. O próprio Rui confessa sua tendência em defender o ensino dessa disciplina na educação secundária e superior, entretanto, curva-se ao exemplo dos países civilizados onde a história, inseparável do ensino da geografia, fazia parte do ensino das primeiras letras. A história a ser ensinada na escola primária haveria de ser, portanto, a história local tendo a pátria como núcleo. Dessa maneira, a história tornava-se um meio útil para o desenvolvimento de sentimentos e faculdades nascentes nas crianças. Significava dizer que o mais importante era dispor o espírito das crianças para a ciência. Por isso, ganham relevo as indicações sobre o uso de fontes historiográficas, cujo conteúdo surpreende pela contemporaneidade: 
O sentimento da realidade na história pode, para o menino, derivar da idéia da história dele mesmo. Está nas mãos do professor induzi-lo a pesquisar os fatos de sua vida pessoal, levando-o a entender o modo como esse passado é o que constitui a história. (...) O professor não enarrará ele mesmo; mandará investigar por todos os modos. Incumbirá os alunos de fixarem uma data. Um livro de per si só não aceitará como prova suficiente; mas se quererá o depoimento de pessoas que hajam sido testemunhas, medalhas, inscrições monumentais, etc. Exercícios desta natureza inclinarão o menino para o verdadeiro sentimento da história. (ibidem)

A concepção de tempo e fato histórico articulava-se a uma compreensão de documento e à história como ciência que solicitava a imaginação das crianças: "ninguém, ao parecer, refletiu ainda em que os verdadeiros elementos da história não consistem no fato de referir histórias, mas na aquisição de noções elementares acerca dos documentos e da maneira de apurá-los" (ibidem).

Para o desenvolvimento desse ensino o mestre deveria considerar os seguintes recursos: primeiro, a investigação do aluno; depois, a palavra do mestre; por último, os livros de leitura. Destacam-se, ainda, a ênfase dada à lição oral, a narração dos grandes fatos da história nacional feita pelo mestre de forma eloqüente e o emprego do método anedótico que se tornou tão popular e arraigado no ensino de história nas séries iniciais no Brasil. A forma anedótica, esclarecia Rui, não significava adotar a forma biográfica, mas proceder à escolha dentre os sucessos mais memoráveis da pátria e da humanidade os que melhor se prestassem à ação dramática, um bom meio de impressionar a criança.

No amplo conjunto de assuntos novos introduzidos no programa do ensino primário, Rui propôs, ainda, os rudimentos de economia política como componente curricular indispensável para a educação das classes populares e das camadas operárias. A economia política, compreendendo noções sobre a riqueza, sua produção, distribuição e caráter, era vista como complemento forçoso da geografia, da história, das noções de direito social e direito pátrio. O ensino dessa disciplina tinha uma finalidade ideológica explícita para o relator, isto é, cimentar a ordem social desigual vigente.

Vemos, dessa maneira, como questões ou temas sociais foram incorporados ao currículo com uma intencionalidade muito clara.

A educação moral e a educação cívica foram, também, incluídas no programa escolar. A concepção de educação moral em apreço pôs em evidência a secularização da moral de natureza cívica em substituição à moral religiosa. 
Concebida não como um curso de estudos no programa mas como elemento que envolvia todos os outros conteúdos, à educação moral cabia um papel fundamental no projeto de educação popular: "É , com efeito, profunda convicção nossa que a influência melhoradora, prosperadora, civilizadora da instrução popular depende absolutamente da sua associação contínua, íntima, indissociável à substância do cultivo moral" (ibidem).

Convinha, pois, desenvolver sentimentos e hábitos, cultivar valores morais desejáveis, tais como: respeito à ordem, disciplina, abnegação, tolerância, amor ao dever, apreço ao trabalho, frugalidade, o bom emprego do tempo, probidade, sinceridade, autocontrole, decência, lealdade, caridade, amor à pátria. Para tanto, o melhor método seria o exemplo, a ação prática do mestre: "o caráter, a ação pessoal do mestre, é o eixo, é o segredo irresistível de toda a educação moral" (ibidem).

Vinculada à educação moral, a educação cívica era tida como uma de suas faces. Tratava-se, eminentemente, da educação patriótica alicerçada sobre os valores morais e intimamente relacionada com a história e a geografia.

A análise realizada neste texto mostrou como o novo programa proposto para o ensino primário brasileiro, no final do século XIX, consistiu em um projeto cultural de alcance social e político.

A ampliação do programa com a introdução de novos saberes objetivando desenvolver a educação física, intelectual e moral significou para as camadas populares maiores oportunidades de acesso à cultura. No entanto, esse saber enciclopédico sumário tinha um caráter de classe e compreendia a cultura disponibilizada para a instrução popular.

Não obstante, as concepções que nortearam a seleção dos conteúdos de ensino e definiram as suas finalidades revelam a configuração de um projeto político-social civilizador, isto é, um projeto nitidamente direcionado para a construção da nação, para a modernização do país, a moralização e a disciplinarização do povo.

Da perspectiva da construção social do currículo é possível destacar vários aspectos. Em primeiro lugar, a diversidade de influências internacionais presentes não apenas no pensamento de Rui Barbosa, mas na constituição do campo educacional no Brasil. Se foi forte a influência americana não foi menor a influência européia. Essa constatação permite matizar a discussão sobre a importação de idéias e a circulação de modelos. A renovação do programa escolar ocorreu em consonância com o debate internacional e revela os confrontos e problemas verificados no processo de consolidação do currículo moderno. 
Esse currículo representou uma profunda transformação na cultura escolar, isto é, a substituição de uma escola fundamentada no ensino da leitura, da escrita, do cálculo e da doutrina cristã, por uma escola pautada na educação do corpo, na ciência, nos valores morais e cívicos e nos saberes instrumentais para o trabalho. A conformação dessa cultura escolar ampliada foi fruto de um longo e conflituoso processo de escolarização de saberes oriundos de fontes diversas. Essa adaptação pedagógica, tendo em vista a aprendizagem infantil, efetivou-se, especialmente, mediante o método intuitivo.

A discussão teórica sobre os programas escolares foi bastante incipiente no período estudado. A questão dos programas mobilizou, por um lado, o debate político sobre a seleção cultural para o povo e, por outro lado, a discussão pedagógica sobre os métodos de ensino.

No contexto da inovação educacional do século XIX, a prescrição do que e como ensinar teve um caráter instituinte à revelia das práticas e dos saberes instituídos. As transformações no ensino primário implicaram uma nova maneira de conceber e praticar o ensino. A adoção da pedagogia moderna redundou na exigência de um novo modelo de professor e trabalho docente, em uma nova organização da escola primária e no uso ampliado de materiais didáticos.

\section{Notas}

1. Embora o parecer sobre a reforma do ensino primário tenha sido apresentado ao Parlamento em 12 de setembro de 1882, a publicação do volumoso trabalho incluindo os anexos foi concluída em 1883, data efetiva de aparecimento desse documento. De fato, Rui Barbosa apresentou ao Parlamento brasileiro dois pareceres em 1882: um sobre a reforma do ensino secundário e superior e outro sobre o ensino primário. Os Pareceres foram elaborados para servir de subsídio à discussão do projeto de Reforma do Ensino Primário e Secundário no Município da Corte e Superior em todo o Império em substituição à reforma instituída por Leôncio de Carvalho em 1879.

2. Para quem interessar, uma análise minuciosa dos Pareceres de Rui Barbosa pode ser encontrada em Valdemarin 2000.

3. Citado no prefácio de Américo Jacobina Lacombe no volume X, tomo I, da edição das Obras Completas de Rui Barbosa, publicadas em 1947.

4. Em relação à difusão do método intuitivo, Rui Barbosa dedicou-se, também, à tradução do livro de Norman Allison Calkins intitulado Primary object lessons, publicando-o no Brasil em 1886, com o título Primeiras lições de coisas. Para uma análise aprofundada do método intuitivo e do Manual de Calkins, ver Valdemarin 1998.

5. As citações da obra de Rui Barbosa encontradas neste texto dizem respeito à Reforma do Ensino Primário, volume X, tomo II, e serão referenciadas da seguinte forma: (Barbosa 1883).

6. A propósito ver Goodson 1997 e Chervel 1998. 
7. Ainda são poucos os estudos sobre a história do ensino de música no ensino primário e secundário no Brasil. A propósito, é notável a influência do nacionalismo nessa história. A respeito, podem-se destacar dois momentos importantes: a criação do Orfeão Infantil Paulista, em 1925, atividade curricular obrigatória para os alunos do terceiro e quarto anos dos grupos escolares no estado de São Paulo, e a introdução oficial do canto orfeônico como disciplina obrigatória nos currículos do ensino secundário na década de 1930.

8. De acordo com Goodson (1997), um forte movimento em prol das ciências das coisas comuns ocorreu na Inglaterra na década de 1850, resultando em uma política financiada pelo governo inglês tendo em vista a produção de material didático, o equipamento das escolas e a formação de professores. A reação incisiva das classes médias e altas contra essa iniciativa bem-sucedida de educação científica de massas provocou o desmantelamento das ciências das coisas comuns substituindo-as por uma ciência laboratorial pura ligada à elite universitária e ao ensino secundário.

9. Ver a respeito as opiniões contidas nas Actas e Pareceres do Congresso de Instrucção do Rio de Janeiro, 1884

10. Sobre o desenvolvimento do ensino de ciências nas escolas primárias paulistas, ver Souza 1998, 1999.

\section{The Educational Innovation in the 19th. Siglo: The renewal of the program of the primary school in Brazil}

ABSTRACT: The text reconstitutes the process of renewal of the programs of the primary school in Brazil starting from 1870, placing the educational modernization in the country in relation to the international context. For this study, we used as research source Rui Barbosa's opinion concerning the Reform of the primary teaching and several complemental institutions of the public instruction (1883), especially the volume regarding the discussion on methods and the school program. Allso demonstrate, as the program it constitutes a project political social civilizador, addressed to build the nation, to modernize the country and to moralize the people.

\section{Bibliografia}

ACTAS e Pareceres do Congresso de Instrucção do Rio de Janeiro. Rio de Janeiro: Tipografia Nacional, 1884.

BARBOSA, R. Reforma do ensino primário e várias instituições complementares da instrução pública (1883). Rio de Janeiro: Ministério da Educação e Saúde, 1947 (Obras Completas, v. 10, t.1-4).

CHERVEL, A. "História das disciplinas escolares: Reflexões sobre um campo de pesquisa". Teoria \& Educação, v. 2, 1990. 
La culture scolaire: Une approche historique. Paris: Belin, 1998.

FARIA FILHO, L.M. "Estado, cultura e escolarização em Minas Gerais no século XIX". In: VIDAL, D.G. e SOUZA, M.C.C. A memória e a sombra. Belo Horizonte: Autêntica, 1999, pp. 117-136.

GOODSON, Ivor. Currículo: Teoria e história. Petrópolis: Vozes, 1995.

A construção social do currículo. Lisboa: Educa, 1997.

HÉBRARD, J. "A escolarização dos saberes elementares na época moderna". Teoria \& Educação, v. 2, 1990, pp. 65-110.

HILSDORF, M.L. "Escolas americanas de confissão protestante na província de São Paulo: Um estudo de suas origens". Dissertação (Mestrado em Educação) - Faculdade de Educação, Universidade de São Paulo, 1977.

KAMES, D. e CHA, Y. "La legitimación de nuevas asignaturas en la escolarización de masas: Orígenes (siglo XIX) y difusión (siglo XX) de la enseñanza del arte y de la educación física". Revista de Estudios del Curriculum, v. 2, nำ1, 1999, pp. 62-86.

MEYER, J.W. et al. School knowlodge for the masses: World models an national primary curricular categories in the twentieth century. Washington/ Londres: The Falmer Press, 1992.

NETO, A.F. (org.). Pesquisa histórica na educação física. Vitória: Ufes, 1997.

PETITAT, A. A produção da escola, produção da sociedade: Análise sóciohistórica de alguns momentos decisivos da evolução escolar no Ocidente. Porto Alegre: Artes Médicas, 1994.

SOARES, C.L. Educação física: Raízes européias e Brasil. Campinas: Autores Associados, 1994.

Imagens da educação no corpo: Estudo a partir da ginástica francesa no século XIX. Campinas: Autores Associados, 1998.

SOUZA, R.F. Templos de civilização: A implantação da escola primária graduada no estado de São Paulo (1890-1910). São Paulo: Editora da Unesp, 1998.

. "Ciencia y moral en la escuela primaria: Un proyecto favorable al orden y la construcción de la nación brasileña". In: Revista de Estudios del Curriculum, v. 2, janeiro, 1999, pp. 115-144. 
SPENCER, H. Educação: Intellectual, moral e physica. Porto: Casa Editora Alcino Aranha, 1884.

VAGO, T.M. "Cultura escolar, cultivo de corpos. Educação physica e gymnastica como práticas constitutivas dos corpos de crianças no ensino público primário de Belo Horizonte (1906-1920)". Tese (Doutorado em Educação), Universidade de São Paulo, 1999.

VALDEMARIN, V.T. "Método intuitivo: Os sentidos como janelas e portas que se abrem para um mundo interpretado". In: SOUZA, R.F.; VALDEMARIN. V.T. e ALMEIDA, J.S. O legado educacional do século XIX. Araraquara: FCL/Unesp, 1998, pp. 63-106.

O liberalismo demiurgo. São Paulo: Cultura Acadêmica, 2000.

VALENTE,W.R. Uma história da matemática escolar no Brasil (1730-1930). São Paulo: Annablume/Fapesp, 1999. 